\title{
MULTINOMIAL LOGISTIC MODELS EXPLAINING INCOME CHANGES OF MIGRANTS TO HIGH- AMENITY COUNTIES
}

\author{
Christiane von Reichert and Gundars Rudzitis ${ }^{*}$
}

\begin{abstract}
A survey of residents of and migrants to 15 fast-growing wildemess counties showed that only 25 percent of the migrants increased their income, while almost 50 percent accepted income losses upon their moves to high-amenity counties. Concomitantly, amenities and quality of life were more important factors in the migration decision than was employment, for instance. We focused on migrants in the labor force and employed multinomial logistic regression to identify the impact of migrants' characteristics, their satisfaction/dissatisfaction with the previous location (push), and the importance of destination features (pull) on income change. We found that migrants in higher age brackets were more inclined to accept lower incomes than younger migrants, while few migrants in high income groups had experienced income cuts. Migrants who moved for employment reasons typically realized income gains, while quality of life oriented moves tended to be associated with income losses.
\end{abstract}

\section{INTRODUCTION}

For decades, migration research has argued that individuals or households move with the goal of maximizing economic returns (Sjaastad 1962). Migrants are expected to increase earned income over the cost of the move. Sjaastad's human capital, as well as macroeconomic theories of migration (Hicks 1932), proposes that migration is largely unidirectional from areas of low to high wages.

Today, the simple income maximization model is no longer accepted as adequate in explaining migration trends in the United States. For example, Krumm (1983) found that while migrant households experience higher wage growth after migration than before, there was no systematic movement from or to areas with high or low wages.

Survey-based research indicates that about 50 percent of the migrants to nonmetropolitan areas encounter a decline in income after migration (Ploch 1978; Sofranko and Williams 1980; Stevens 1980; Rudzitis and Johansen 1991b). We will use survey data from the Rudzitis and Johansen (1989) study of migrants to high-amenity counties to assess the relative importance of socioeconomic demographic characteristics and attitudes in explaining the willingness of

\footnotetext{
*Department of Geography, University of Idaho. We express our appreciation to Brian Dennis, Dale Everson. Thomas Knapp, and the anonymous reviewers for their help and suggestions on an earlier draft of this paper. The data used in this research was obtained under a grant from the National Science Foundation.
} 
migrants in the labor force to accept or not accept losses in income after their move.

\section{BACKGROUND}

Researchers have increasingly recognized that people move and places increase or decrease in population because of a complex combination of factors. The interrelationship between jobs and people is one of cumulative causation; employment attracts migrants, and new migrants lead to increases in employment (Chalmers and Greenwood 1980).

Nonmonetary factors, especially amenities, have become recognized as important reasons for people to migrate. Ullman (1954) was among the first to cite amenities as a major factor in the regional growth process. Since then, a number of studies have shown amenities to be important in the migration process (Graves 1979, 1983; Rudzitis 1979; Briggs and Rees 1982; Swanson 1986; Cushing 1987).

The importance of amenities may provide an explanation of why income may not be as important as expected, since people may accept lower wages and incomes if they are compensated by a potentially wide range of amenities. Indeed, one argument is that migration takes place as a result of change in demand for location-specific amenities (Graves and Linneman 1979; Linneman and Graves 1983). An advantage of the location-specific amenities approach is that, unlike the traditional job search model, differences between areas in wages and incomes need not result in migration from low-wage to high-wage areas, since interregional wage differences are assumed to be compensating differentials. People will move in response to changing preferences, induced, for instance, by either a rise or fall in income (Knapp and Graves 1989).

The relative importance of economic or location-specific amenities in the migration process remains controversial. Porell (1982) finds that both economic and quality of life factors are important but suggests that migration is more responsive to marginal changes in economic factors than to quality of life factors. Greenwood and Hunt (1989) argue that economic factors are more important. Other studies (Graves 1979, 1980, 1983; Liu 1975; Hsieh and Liu 1983; Rudzitis and Johansen 1989, 1991a) find amenities to be important. Evans (1990) asserts that a major question is whether amenities or jobs are the most important determinants of migration.

Much of the income and jobs debate takes place within the context of metropolitan migration, but survey research documenting the importance of amenities has been based primarily on migration to nonmetropolitan areas, par- 
ticularly during the "rural renaissance" of the 1970s. National surveys (Zuiches and Fuguitt 1976; Morgan 1978) also found a preference for living in small towns.

If preferences lead to migration, and here the evidence is scarce (Fuguitt 1985), more migration to traditionally lower-wage, higher-amenity areas might be expected. Despite the current reversal of migration trends with metropolitan areas growing faster than nonmetropolitan areas, Frey (1988) sees little likelihood that migration trends will signal a return to the metropolis. Instead, the 1980 migration processes imply a continued redistribution from core to peripheral regions and migration stream exchanges that run down the metropolitan area hierarchy.

Movements down the urban hierarchy to more peripheral regions and especially to nonmetropolitan areas suggest that more migrants may trade income for increased amenities and quality of life. To our knowledge, there has not been much research into how, why, and when people trade income for amenities, nor what distinguishes those migrants who willingly do so from others who do not.

Zuiches and Fuguitt (1976) found that one-half of those persons preferring nonmetropolitan areas would give up their preference when potential income declines were a condition of the move. Similarly, Carpenter (1977) found that while 52 percent would prefer to live in a community of less than 50,000 people, only 3 percent were interested in moving if it involved a loss of income. Stevens (1980) used a hedonic approach and tried to explain-with limited success-income sacrifices after migration to nonmetropolitan counties. In contrast, Hodge (1985) found that unemployed workers in a depressed nonmetropolitan area would be willing to accept substantially lower earnings to avoid moving away from the area. Recently, some researchers have argued that commitment to place and a sense of place (Bolton 1989; Rudzitis 1989, 1991a) may keep people loyal to a community or rural landscape, even when that location provides them with little material value (Marsh 1987).

\section{FIFTEEN-COUNTY SURVEY}

The data used in this study comes from a survey of 15 high-amenity counties selected from 277 wilderness counties in the United States. "Wilderness counties" contain or are adjacent to a federally designated wilderness area. In these counties, a range of amenities is held constant, while others, such as climate, vary. Amenities such as access to pristine areas and lower pollution levels will vary little, if at all. For example, only minimal deterioration in air quality is allowed in these areas (Rudzitis and Johansen 1989a) because government regulations have made pollution levels much lower in these counties, which has thus made them 
more attractive. Therefore, it seems reasonable to view wilderness counties as high-amenity counties. Wilderness counties have grown at a rate two to three times higher than metropolitan and nonmetropolitan counties during the 1970s and 1980 s as well as in prior decades. We selected 15 wilderness counties that experienced very high population growth during the 1970 s and the first half of the 1980s and that were not adjacent to metropolitan areas (Table 1).

The respondents were randomly selected from the current population. A mail

TABLE 1

Population Growth of Sampled Wilderness Counties, 1970-1985

\begin{tabular}{llcc}
\hline \hline State & County & \% Change 1970-80 & \% Change 1980-85 \\
\hline Arizona & Coconino & 55.1 & 13.5 \\
California & Lassen & 29.0 & 12.6 \\
California & Trinity & 55.7 & 13.4 \\
Colorado & Eagle & 77.6 & 21.4 \\
Georgia & Charlton & 29.3 & 3.5 \\
Idaho & Valley & 55.4 & 20.0 \\
Kentucky & Pulaski & 30.0 & 6.1 \\
Missouri & Stone & 57.1 & 12.6 \\
Montana & Lake & 31.9 & 9.6 \\
New Hampshire & Carroll & 50.6 & 10.1 \\
New Mexico & Lincoln & 45.5 & 26.1 \\
Oregon & Deschutes & 104.0 & 7.1 \\
Utah & Wasatch & 45.4 & 12.8 \\
Washington & San Juan & 103.3 & 15.6 \\
Wyoming & Teton & 94.0 & 15.4 \\
\hline Percentage change for 15 counties & 55.0 & 11.0 \\
\hline
\end{tabular}

survey was used in a modified Dillman (1978) total design method, with 3,754 returned questionnaires for a 36 percent response rate. Responses were nearly equally divided among long-term residents $(1,930)$ and migrants $(1,824)$. A person was considered a migrant if he or she had moved to the wilderness county since 1975. At a 95 percent confidence level, the overall sample has a sampling error of 3 percent.

\section{DATA}

Among the migrants, 1,750 marked one of five response categories to the question, "When you first moved here, how did your total annual household income change?" (Table 2). Only 25 percent had an increase in income after 
moving. Almost half of the surveyed migrants (47 percent) lost income. These results certainly are not compatible with the income maximization approach, but they would be expected if retired people were the primary migrants to these counties. Excluding retired migrants, there are 1,283 persons in the sample. The share of income gainers increased from 25 percent to 30 percent, but still 45 percent of the migrants in the labor force lost income (Table 2). The following analysis of income change uses only data on labor force migrants.

\section{TABLE 2}

Income Change of Migrants to Wilderness Counties

\begin{tabular}{|c|c|c|c|c|c|}
\hline \multirow{2}{*}{$\begin{array}{l}\text { Income Change } \\
\text { Gain }>+\$ 5,000\end{array}$} & \multirow{2}{*}{$\begin{array}{c}\text { Category } \\
0\end{array}$} & \multicolumn{2}{|c|}{$\begin{array}{l}\text { Surveyed Migrants } \\
\text { to Wilderness Counties }\end{array}$} & \multicolumn{2}{|c|}{$\begin{array}{l}\text { Labor Force Migrants } \\
\text { (excluding retired) }\end{array}$} \\
\hline & & 225 & $12.8 \%$ & 203 & $15.8 \%$ \\
\hline$\$ 1,000$ to $\$ 5,000$ gain & 1 & 215 & $12.3 \%$ & 186 & $14.5 \%$ \\
\hline \pm Same & 2 & 419 & $28.0 \%$ & 312 & $24.3 \%$ \\
\hline$-\$ 1,000$ to $-\$ 5,000$ loss & 3 & 184 & $10.5 \%$ & 144 & $11.2 \%$ \\
\hline \multirow[t]{2}{*}{ Loss $<-\$ 5,000$} & 4 & 639 & $36.4 \%$ & 438 & $34.1 \%$ \\
\hline & & 1754 & $100.0 \%$ & 1283 & $100.0 \%$ \\
\hline
\end{tabular}

Note: Our analysis of income change is restricted to migrants in the labor force.

We should emphasize that these are not adjusted or real income changes. Metropolitan migrants to these nonmetropolitan counties can be expected to have lower living costs and may have no loss in real income. Unfortunately, the federal cost-of-living surveys do not extend to areas such as ours, a strange and cavalier omission given as Fuguitt, Brown, and Beale (1989) point out the tens of millions of people who live in such places. Hoch, Hewitt, and Virgin (1984) assumed that wage differences between metropolitan and nonmetropolitan regions are compensatory and estimated that in nominal terms, nonmetropolitan per capita income was 75 percent of that in metropolitan areas, but 89 percent in real terms. Given that in our sample close to 40 percent of the migrants were from other nonmetropolitan areas, the true difference is considerably narrowed, but not eliminated.

We have tried to adjust for cost-of-living differences by supplementing our survey data with aggregate data, namely 1980 Census data of medium housing values (U.S. Census Bureau 1988). The expenditure for housing constitutes a considerable share of household expenditure, and differences in housing values may be indicative of general differences in cost of living. DIFFVAL, our proxy for differences in cost of living, is defined as 1980 medium housing values in the des- 
tination county minus 1980 medium housing values in the origin county (in $\$ 1,000$ ). Therefore, negative values reflect lower cost of living in the destination county compared with the origin county, and vice versa for positive values.

From the survey, we use three major components as sets of explanatory variables: characteristics of migrants, such as age, income, and education (Table 3); attitudes toward the origin county, which contain information as to why migrants left; and attitudes toward the destination county, which provide insight into why migrants selected the destination (Table 4). Previous survey research has suggested that migration involves making more than one decision. If there is more

TABLE 3

Variables: Characteristics of Migrants

\begin{tabular}{|c|c|c|c|}
\hline INCOME & Household income at survey & $\begin{array}{l}1<\$ 5,000 \\
3=<\$ 15,000 \\
5=<\$ 35,000 \\
7=<\$ 60,000\end{array}$ & $\begin{array}{l}2=<\$ 10,000 \\
4=<\$ 25,000 \\
6=<\$ 45,000 \\
8>\$ 60,000\end{array}$ \\
\hline EDUCAT & Education & \multicolumn{2}{|c|}{$\begin{array}{l}1=\text { no formal education }<8 \text { yrs. } \\
2=\text { completed grade school }=8 \mathrm{yrs} .+ \\
3=\text { completed high school }=12 \mathrm{yrs} \text {. } \\
4=\text { some technical/trade school }= \pm 13 \text { yrs. } \\
5=\text { completed technical/trade school }=14 \mathrm{yrs} \text {. } \\
6=\text { some college }=13-15 \mathrm{yrs} \text {. } \\
7=\text { completed college }=16 \mathrm{yrs} . \\
8=\text { completed graduate work }=18 \mathrm{yrs} .+\end{array}$} \\
\hline AGE & Age at survey & $\begin{array}{l}1=<20 \text { yrs. } \\
3=36-50 \\
5=65+\end{array}$ & $\begin{array}{l}2=21-35 \\
4=51-65\end{array}$ \\
\hline POPRAISE & $\begin{array}{l}\text { Describes the community } \\
\text { where migrant typically } \\
\text { lived until age } 18\end{array}$ & \multicolumn{2}{|c|}{$\begin{array}{l}1=\text { rural residence, farm, ranch } \\
2=\text { small town }<5,000 \\
3=\text { large town }(5-25,000) \\
4=\text { small city }(25-100,000) \\
5=\text { large city }(100,000+) \\
6=\text { suburban area adjacent to large city }\end{array}$} \\
\hline METNOMET & Metro or nonmetro origin & $1=$ metro & $2=$ nonmetro \\
\hline GENDER & Gender & $1=$ male & $2=$ female \\
\hline
\end{tabular}

than one decision and more than one behavior, the causes of each behavior need not be the same. The reasons why people leave a place need not be the same as why they choose a place to move to.

The survey questionnaire asked about dissatisfaction/satisfaction with the previous location, often classified as a push factor in the migration literature. We asked: "There are many reasons why people leave a place. How dissatisfied were you with the county you lived in before moving to county?" Migrants were asked to circle one response for each item that followed, with response categories being arranged on an ordinal scale from 1 (extremely dissatisfied) to 5 (not dissatisfied). Items included, for instance, "employment opportunities at previous location," "access to family and friends at previous location," "pace of life at pre- 
vious location," etc. (Table 4). To identify the importance of the attributes of the destination county in the migration decision (pull), we asked: "How important were the following attributes of county in your decision to move here?" The list of attributes was comparable to the previous list of dissatisfaction items and included, for instance, "employment opportunity in county," cost of living in county," "landscape/scenery in county," "environmental quality in county," etc. (Table 4). Response categories for each attribute ranged from 1 (extremely important) to 5 (not important). We will refer to migrants who were highly dissatisfied with employment opportunities at the previous location and/or migrants to whom employment opportunities were important as "employment oriented" and to their moves as "migration for employment reasons." Similarly, migrants dissatisfied with pace of life, environmental quality, or other dimensions of quality of life and/or migrants who marked quality of life variables as important may be classified as "quality of life oriented."

For information purposes, we show the relative dissatisfaction scores with

TABLE 4

Variables: Attitudes of Migrants

\begin{tabular}{lccc}
\hline \hline & & & \\
PUSH Variables & Dissatisfaction with Previous Location & Dissatisfled & Not Dissatisfied \\
\hline CHILDRN & Place to raise children & $29 \%$ & $49 \%$ \\
CLIMAT & Climate & $21 \%$ & $63 \%$ \\
COSTLIV & Cost of living & $14 \%$ & $64 \%$ \\
CRIMRAT & Crime rate & $28 \%$ & $50 \%$ \\
EMPLYMNT & Employment opportunities & $19 \%$ & $61 \%$ \\
ENVQUAL & Environmental quality & $30 \%$ & $58 \%$ \\
FAMACES & Family access & $12 \%$ & $75 \%$ \\
OUTDREC & Outdoor recreation & $18 \%$ & $63 \%$ \\
PACELIF & Pace of life & $30 \%$ & $48 \%$ \\
SCENRY & Scenery & $20 \%$ & $62 \%$ \\
PULL Variables & Importance in moving to current location & Important & Not Important \\
& (Wildemess County) & $44 \%$ & \\
\hline CHILDR & Place to raise children & $45 \%$ & $30 \%$ \\
CLIMAT & Climate & $14 \%$ & $57 \%$ \\
COSTLIVE & Cost of living & $31 \%$ & $45 \%$ \\
CRIMERAT & Crime rate & $38 \%$ & $44 \%$ \\
EMPLOYOP & Employment opportunities & $63 \%$ & $18 \%$ \\
ENVIQUAL & Environmental quality & $18 \%$ & $66 \%$ \\
FAMACCES & Family access & $57 \%$ & $19 \%$ \\
OUTDRREC & Outdoor recreation & $60 \%$ & $15 \%$ \\
PACELIIF & Pace of life & $70 \%$ & \\
SCENERY & Scenery & & \\
& & & \\
\hline
\end{tabular}

\footnotetext{
*dissatisfied $=$ extremely (1) or very (2)

**important $=$ extremely (1) or very (2)

not dissatisfied $=$ little (4) or not (5)

not important $=$ little (4) or not (5)
}

the previous residence and the importance scores for attributes of the wilderness county (Table 4). On the push side, dissatisfaction is not high on most items, yet certain items such as environmental quality, pace of life, crime rate, scenery, and outdoor recreation have higher levels of dissatisfaction than economic considera- 
tions such as employment opportunities and cost of living. Of the pull factors, we see the major importance placed on scenery, environmental quality, pace of life, outdoor recreation, and other natural amenity measures. Employment opportunities and cost of living are of less importance.

\section{HYPOTHESES}

Relocation to high-amenity wilderness areas represents a highly selective type of migration. Population growth of the wilderness counties should be a result of migrants moving to these areas because of a demand for amenities expressed in the greater availability of environmental goods, recreational opportunities, and a perceived higher quality of life. Given the greater supply of amenities derived from the physical environment and our observations about income change, a considerable share of migrants moved to improve their quality of life, not their economic position. Are income losses a price for increased quality of life in these counties? Do income losses represent migrants' willingness to pay for amenities found in wilderness counties? What distinguishes migrants who were willing to accept income losses from migrants who increased their incomes with migration? Can we identify regularities that tie changes in income (gains and losses) to migrants' characteristics or attitudes? These are the questions we posed.

If reduction in income is the price migrants to amenity counties are willing to pay for a higher quality of life, we would expect migrants who are highly dissatisfied with the quality of life at the previous location to be inclined to accept income reductions. Conversely, migrants who were not dissatisfied with living conditions would probably not be among income losers. Furthermore, if quality of life were an important reason why a destination county was chosen, the migrant would be willing to accept lower income and feel compensated with amenities. Migrants who moved for reasons other than amenities-for instance, migrants who moved for employment reasons-would show little inclination to accept income losses.

We hypothesize that quality of life is a superior good as cited in the amenities literature (Graves and Linneman 1979). The higher the level of income, the greater the quest for quality of life and the willingness of migrants to highamenity counties to accept greater income reductions. We also expect the willingness to accept income losses to increase with education.

It seems reasonable to expect that income gains are more important to young migrants, while income reductions are acceptable to older migrants, since migration studies suggest that-on average-income is maximized before age 55 (Graves 1980). Occurrence of income gain or income loss may also differ for male or 
female migrants, but we have no prior expectation about gender-specific differences.

Finally, we want to explore whether the residential history, such as the type of community migrants were raised in or migration from metropolitan or nonmetropolitan counties, has an impact on migrants' willingness to accept income losses. Migrants who left metropolitan areas to move to a wildemess county should be more willing to accept losses if the differences in the level and quality of amenities are greater than those for people moving from nonmetropolitan areas with physical and social environments more similar to the wilderness county.

\section{METHODOLOGY}

Measured on a continuous scale, income change is a quantitative variable. In the survey, information about income change was obtained and coded as an ordinal variable with five levels. It is inappropriate to use ordinary least squares (OLS) regression with a dependent categorical variable, because OLS assumptions are violated. Logit models are designed for analysis of discrete data. Logit models are appropriate if dependent and independent variables are categorical, either nominal or ordinal (Agresti 1984, 1990; Nelson and Aldrich 1984). Logistic regression is an extension of logit models if one or more of the independent variables are ordinal or quantitative (Hosmer and Lemeshow 1989).

Logit models and logistic regression can be used with a binomially or multinomially distributed dependent variable. Conversion of discrete data to probabilities allows us to represent the probabilities for discrete events $(Y=0,1 \ldots, k)$ as nonlinear functions of independent variables. For a binary dependent variable $(Y=0,1)$, the $S$-shaped curve corresponds to a logistic function of the form

$$
p(Y=1)=\frac{e^{a+b x}}{1+e^{a+b x}}=\frac{1}{1+e^{-a-b x}}
$$

or

$p(Y=0)=1-p(Y=1)=\frac{1}{1+e^{a+b x}}$

as

$p(Y=1)+p(Y=0)=1$

If response variables are polytomous (e.g., $Y=0,1, \ldots j \ldots k$ ) and ordinal, cumulative logits (Agresti 1990, 1984) or proportional odds models (Harrell 
1986) are appropriate. Multinomial logistic regressions with $k+1$ categories have $k$ intercept terms, and for $j=1,2, \ldots k$, the cumulative probability of $Y \geq j$ is

$$
p(Y \geq j)=\frac{1}{1+e^{-a_{j}-b x}}
$$

respectively the probability of $Y<j$ is

$$
p(Y<j)=1-p(Y \geq j)=\frac{1}{1+e^{a_{j}+b x}}
$$

Individual probabilities, for instance for $Y=j$, can be derived as the difference between cumulative probabilities for $j$ and $j+1$

$$
p(Y=j)=p(Y \geq j)-p(Y \geq j+1)
$$

We are using the polytomous variable income change (INCCHANG) with five ordinal categories and $k=4$. Category 0 represents relatively large income gains of more than $\$ 5,000$, while category 4 includes relatively large income losses of more than $\$ 5,000$. Intermediate categories of income change are ordered and take positions 1 through 3 (Table 2). Estimated probabilities for migrants belonging either to categories 1 through 4 , (3a), or otherwise to category 0 , (3b), can be derived from the estimated intercept term a $\mathrm{a}_{1}$ and coefficient estimates as follows:

$$
\begin{aligned}
& p(\text { INCCHANG } \geq 1)=p \text { (income change } \leq \$ 5,000)=\frac{1}{1+e^{-a_{1}-b x}} \\
& p(\text { INCCHANG }=0)=p(\text { income change }>\$ 5,000)=1-p(\text { INCCHANG } \geq 1) \\
& =1-\frac{1}{1+e^{-a_{1}-b x}}=\frac{1}{1+e^{a_{1}+b x}}
\end{aligned}
$$

To estimate cumulative probabilities, for instance the probability to incur income loss (category 3 or category 4 and therefore $j \geq 3$ ), use appropriate intercept terms, here a3. Probabilities to experience large income losses exceeding $\$ 5,000$ (category $4, j=4$ ) can be estimated with a4.

$$
p(\text { INCCHANG }=4)=p(\text { income change }<-\$ 5,000)=\frac{1}{1+e^{-a_{4}-b x}}
$$




\section{RESULTS}

Table 5 summarizes the findings from five stepwise logistic regressions of income change. The variable DIFFVAL, which adjusts for differences in average cost of housing between origin and destination counties, is forced to enter all models.

Model 1 (characteristics model) ties the likelihood that a migrant experiences income change, i.e., income loss, to the characteristics of that migrant. Models 2 through 5 include attitudinal variables as predictors of income change. While characteristics frequently are independent variables in migration studies, the impact of attitudes on migration behavior is relatively unexplored. Model 2 (push factor model) captures dissatisfaction with the previous location and its effect on income change. Model 3 (pull factor model) tries to explain the probability of income change with a migrant's attitudes about the destination county. Model 4 combines attitudinal variables (push and pull). Model 5 is a composite model of characteristics and attitudes.

All variables from Table 3 and Table 4-as they are relevant to the five models specified-enter the stepwise procedures, but only significant variables are shown in Table 5. Reported are the coefficient estimates, the significance levels (in parentheses), and the model chi-squares with degrees of freedom and significance levels. We used a conservative rule suggested by Harrell (1986) and stopped the stepwise procedure when the residual chi-squares became insignificant.

\section{Characteristics}

In the following, we will describe characteristics of migrants as they relate to income change. AGE is a highly significant variable in the characteristics model. The estimated coefficient is positive, which indicates that older migrants are more likely to experience income losses than very young migrants. Even many 35-50-year-olds are accepting losses, while typically during these years, income gains are actively pursued.

High-INCOME groups are, contrary to our expectation, predominantly found among income gainers, while medium- and low-income groups are predominantly found among income losers. The findings seem to undermine the superior hypothesis of quality of life. Of course, we need to be aware that incomes are reported at the time of the survey, not income levels before migration. Therefore, they incorporate migrants' previous willingness to accept income cuts or lower raises while pursuing other goals in life. A comparison of incomes of migrants and long-term residents shows that migrants are in somewhat higher income 
TABLE 5

Results of Multinomial Logistic Regressions

\begin{tabular}{|c|c|c|c|c|c|}
\hline INTERCEPTI & $\begin{array}{c}\text { Characteristics } \\
2.3615 \\
(.0001)\end{array}$ & $\begin{array}{l}\text { Push } \\
1.5798 \\
(.0001)\end{array}$ & $\begin{array}{l}\text { Pull } \\
1.2006 \\
(.0001)\end{array}$ & $\begin{array}{c}\text { Push-Pull } \\
.7436 \\
(.0040)\end{array}$ & $\begin{array}{r}\text { Composite } \\
.8544 \\
(.0151)\end{array}$ \\
\hline INTERCEPT2 & $\begin{array}{l}1.3899 \\
(.0001)\end{array}$ & $\begin{array}{l}.6006 \\
(.0261)\end{array}$ & $\begin{array}{r}.2272 \\
(.2229)\end{array}$ & $\begin{array}{l}-.2553 \\
(.3209)\end{array}$ & $\begin{array}{l}-.1945 \\
. .5786)\end{array}$ \\
\hline INTERCEPT3 & $\begin{array}{r}.2079 \\
.5185)\end{array}$ & $\begin{array}{l}-.6262 \\
(.0205)\end{array}$ & $\begin{array}{r}-.9907 \\
(.0001)\end{array}$ & $\begin{array}{r}-1.5169 \\
(.0001)\end{array}$ & $\begin{array}{l}-1.4786 \\
(.0001)\end{array}$ \\
\hline INTERCEPT4 & $\begin{array}{l}-.3247 \\
(.3128)\end{array}$ & $\begin{array}{r}-1.1477 \\
(.0001)\end{array}$ & $\begin{array}{r}-1.4996 \\
(.0001)\end{array}$ & $\begin{array}{r}-2.0417 \\
(.0001)\end{array}$ & $\begin{array}{r}-2.0404 \\
(.0001)\end{array}$ \\
\hline DIFFVAL & $\begin{array}{r}-.00625 \\
(.0024)\end{array}$ & $\begin{array}{l}-.00600 \\
(.0042)\end{array}$ & $\begin{array}{r}-.00622 \\
(.0028)\end{array}$ & $\begin{array}{r}-.00357 \\
(.0960)\end{array}$ & $\begin{array}{r}-.00121 \\
(.5870)\end{array}$ \\
\hline AGE & $\begin{array}{l}.4620 \\
(.0001)\end{array}$ & & & & $\begin{array}{l}.4194 \\
(.0001)\end{array}$ \\
\hline INCOME & $\begin{array}{l}-.2378 \\
(.0001)\end{array}$ & & & & $\begin{array}{l}-.2831 \\
(.0001)\end{array}$ \\
\hline METNOMET & $\begin{array}{r}. .5049 \\
(.0001)\end{array}$ & & & & \\
\hline EMPLYMNT & & $\begin{array}{r}.3493 \\
(.0001)\end{array}$ & & $\begin{array}{l}.2328 \\
(.0001)\end{array}$ & $\begin{array}{r}.2644 \\
(.0001)\end{array}$ \\
\hline ENVQUAL & & $\begin{array}{l}. .1517 \\
(.0003)\end{array}$ & & $\begin{array}{r}-.1639 \\
(.0001)\end{array}$ & \\
\hline CLIMAT & & $\begin{array}{r}-.1504 \\
(.0015)\end{array}$ & & & \\
\hline PACELIF & & & & & $\begin{array}{r}. .1286 \\
(.0038)\end{array}$ \\
\hline EMPLOYOP & & & $\begin{array}{r}.3109 \\
(.0001)\end{array}$ & $\begin{array}{r}.2478 \\
(.0001)\end{array}$ & $\begin{array}{l}.2238 \\
(.0001)\end{array}$ \\
\hline PACELIFE & & & $\begin{array}{r}-.1468 \\
(.0011)\end{array}$ & & \\
\hline $\begin{array}{l}\text { MODEL } \\
\text { CHI-SQUARES }\end{array}$ & $\begin{array}{l}121 \\
(.0001)\end{array}$ & $\begin{array}{r}111 \\
(.0001)\end{array}$ & $\begin{array}{r}108 \\
(.0001)\end{array}$ & $\begin{array}{r}137 \\
(.0001)\end{array}$ & $\begin{array}{r}205 \\
(.0001)\end{array}$ \\
\hline df & 4 & 4 & 3 & 4 & 6 \\
\hline
\end{tabular}


groups than residents. These findings seem to be compatible with previous research on postmigration earnings (Farber 1983; Krumm 1983). When controlling for education-and surveyed migrants typically attained higher education levels than surveyed residents-these differences disappear. If moves are amenity oriented, postmigration incomes may change differently than for labor-oriented moves. More research on this topic is clearly called for.

Education (EDUCAT) fails to be a significant explanatory variable; the results do not provide evidence about a link between income change and education levels. Neither do we find GENDER-specific differences in probabilities to accept income loss. While the variable for residential experience at young age (POPRAISE) does not enter the model, the variable for recent residential experience (METNOMET) does; migrants from metropolitan areas are-as hypothesized-more likely to accept income losses than migrants from nonmetropolitan areas.

Differences in the cost of housing (DIFFVAL) and consequently differences in the cost of living do seem to matter: migrants from high-cost areas are more likely to accept income losses than migrants from lower cost areas, therefore receiving smaller losses in real income than nominal income. A move from areas of high housing values to areas of low housing values can result in a capital gain for migrants who were home owners and may increase migrants' inclination to accept lower incomes.

\section{Push Factors}

Next, we compare dissatisfaction with the previous location and income change. The push model suggests that migrants who were dissatisfied with employment opportunities at the previous location (EMPLYMNT) were typically income gainers. Conversely, migrants who were not dissatisfied with employment opportunities at the previous location were predominantly income losers. Dissatisfaction with environmental quality at the previous location (ENVQUAL) was significant. Pronounced dissatisfaction with environmental quality tends to go hand in hand with income loss. Assessment of climatic conditions at the previous location (CLIMAT) is related to income change in a similar manner: dissatisfaction with climate increases migrants' willingness to accept income reductions.

Multicollinearity seems to exist between some attitudinal variables. For example, when the dissatisfaction with environmental quality (ENVQUAL) is eliminated from the model, dissatisfaction with the pace of life at the previous location (PACELIF) enters the model as a significant variable with a similar estimated coefficient. CRIMRAT, the attitudinal variable measuring dissatisfaction with the crime rate at the previous location, behaves similarly. 
The results of the push model provide support for our hypotheses: migrants who moved because they were dissatisfied with the quality of life at the previous location were generally more willing to accept lower incomes after the move. If dissatisfaction with employment opportunities was an important reason for the move, migrants tended to increase their incomes when relocating. As observed in the previous model, differences in housing values appear to be significant predictors of income loss probabilities.

\section{Pull Factors}

The results of the pull model can be summarized as follows: importance of employment opportunities (EMPLOYOP) is a highly significant variable. The positive coefficient implies that migrants who considered employment opportunities as an important pull factor are predominantly among income gainers, whereas migrants who did not move for employment reasons are predominantly among income losers. Pace of life (PACELIFE) proved to be a significant variable. The negative coefficient indicates that migrants tended to accept income cuts if pace of life in the destination county was an important consideration. These findings conform to our expectations-migrants who moved for employment reasons realized higher incomes after the move, while migrants who moved for a higher quality of life were willing to accept income cuts. Coefficients of the cost of living variable are consistent with the previous characteristics model and the push model.

\section{Push and Pull Factors}

The push-pull model considers attitudes toward origin conditions and destination features. Consistent with the push or pull model, both employment variables are significant with somewhat smaller coefficient estimates than in the previous models. The variable measuring dissatisfaction with environmental quality is significant, while dissatisfaction with climate fails to enter this extended model. DIFFVAL, the variable adjusting for differences in cost of housing, is insignificant at the .01 and .05 levels. Some of the significant coefficients in the previous models may be a result of misspecification bias of partial models.

\section{Composite Model}

The composite, or full model, explains the likelihood that migrants experience income cuts with a combination of characteristics, push variables, and pull variables. In this full model, differences in the cost of housing/living con- 
tribute little toward explaining income change because the coefficient of DIFFVAL is highly insignificant. For many migrants, real income reductions may be smaller than nominal income cuts, but we cannot conclude that income changes and differences in the cost of living move in tandem; income losses do not seem to be systematically compensated by lower cost of living.

While dissatisfaction with climate at the previous location and metropolitannonmetropolitan origins does not enter the full model, it is otherwise consistent with the partial models. As stated previously, the composite model suggests that willingness to accept income loss increases with age and decreases with income. Based on attitudes toward employment opportunities at the previous and the current locations, migrants to high-amenity counties can be divided into two unequal groups: a smaller group who moved for employment reasons, and a larger group who did not move for employment reasons. Migrants who moved for employment reasons tended to realize income gains, but migrants who did not move for employment reasons were likely to experience income cuts. Dissatisfaction with the pace of life at the previous location increased the migrants' willingness to accept income losses.

In summary, the characteristics and attitudes that distinguish income losers from income gainers are age, income, attitudes toward employment opportunities, attitudes toward pace of life, and probably related dimensions of quality of life. Income-losing migrants typically are older and of lower to medium income, who did not move for employment reasons but were concerned about quality of life. Migrants who realized income gains tended to be young and of medium- to highincome. They placed little importance on quality of life and moved for employment reasons.

\section{CONCLUSION}

Our survey research of migrants to (and residents of) high-amenity wilderness counties showed that nearly half of all surveyed migrants in the labor force received lower incomes. Concomitantly, amenities and quality of life were more important in attracting migrants in the labor force than employment opportunities, for example. We could establish that significant relationships exist between the type of migrant, the reasons why people moved, and the probability to incur income loss.

To probably a small, but not insignificant, part of the population, quality of life and amenities matter to a degree where lower incomes are acceptable; 86 percent of all migrants (and 90 percent of the residents) were highly satisfied with the 
wilderness county as a place to live, and more than 75 percent considered their lives more enjoyable and happier since the move (Rudzitis and Johansen 1989).

What do our findings suggest for the future of nonmetropolitan amenity counties? Quality of life and location-specific amenities are assets. Concern for these assets and their careful promotion and protection promise to enable nonmetropolitan counties to retain population and attract migrants in search of amenity-rich environments and lifestyles in a decade where many nonmetropolitan counties are-once again-threatened by population loss.

\section{REFERENCES}

Aldrich, J. H., and F. D. Nelson. Linear Probability, Logit and Probit Models. Series: Quantitative Applications in the Social Sciences, no. 45. Beverly Hills, London, and New Delhi: Sage Publications, 1984.

Agresti, A. Analysis of Ordinal Categorical Data. New York, Chichester, Brisbane, Toronto, and Singapore: John Wiley \& Sons, 1984. . Categorical Data Analysis. New York, Chichester, Brisbane, Toronto, and Singapore: John Wiley \& Sons, 1990.

Bolton, R. "An Economic Interpretation of a 'Sense of Place'." Research Paper no. 130. Williamstown, Mass.: Williams College, Department of Economics, 1989.

Briggs, R., and J. Rees. "Control Factors in the Economic Development of Nonmetropolitan America." Environment and Planning 14 (1982): 1645-1666.

Carpenter, E. H. "The Potential for Population Dispersal: A Closer Look at Residential Location Preferences." Rural Sociology 42 (1977): 352-370.

Chalmers, J. A., and M. J. Greenwood. "The Economics of the Rural to Urban Population Turnaround." Social Science Quarterly 61 (1980): 524-544.

Cushing, B. J. "Location-Specific Amenities, Topography, and Population Migration." Annals of Regional Science 21 (1987): 74-85.

Dillman, D. A. Mail and Telephone Surveys: The Total Design Method. New York: John Wiley \& Sons, 1978.

Evans, A. W. "The Assumption of Equilibrium in the Analysis of Migration and Interregional Differences: A Review of Some Recent Research." Journal of Regional Science 30 (1990): 515-531.

Farber, S. C. "Post-Migration Earning Profiles: An Application of Human Capital and Job Search Models." Southern Economic Journal 49 (1983): 693-705. 
Frey, W. H. "Migration and Metropolitan Decline in Developed Counties: A Comparative Study." Population and Development Review 14 (1988): 595-628.

Fuguitt, G. V. "The Nonmetropolitan Population Turnaround." Annual Review of Sociology 11 (1985): 259-280.

Fuguitt, G. V., D. L. Brown, and C. L. Beale. Rural and Small Town America. New York: Russell Sage Foundation, 1989.

Graves, P. E. "Migration With a Composite Amenity: The Role of Rents." Journal of Regional Science 23 (1983): 541-546. . "Migration and Climate." Journal of Regional Science 20 (1980):

227-237. . "A Life-Cycle Empirical Analysis of Migration and Climate By Race." Journal of Urban Economics 6 (1979): 135-147.

Graves, P. E., and P. E. Linneman. "Household Migration: Theoretical and Empirical Results." Journal of Urban Economics 6 (1979): 383-404.

Greenwood, M. J., and G. L. Hunt. "Jobs Versus Amenities in the Analysis of Metropolitan Migration." Journal of Urban Economics 25 (1989): 1-16.

Harrell, F. E. "The LOGIST Procedure." In SUGI Supplemental Library User's Guide, Version 5 ed., 267-293. Cary, N.C.: SAS Institute Inc., 1986.

Hicks, J. R. The Theory of Wages. London: McMillan, 1932.

Hoch, I., J. Hewitt, and V. Virgin. Real Income, Poverty, and Resources. National Center for Food and Agricultural Policy. Washington, D.C.: Resources for the Future, 1984.

Hodge, I. D. "Employment Expectations and the Costs of Migration." Journal of Rural Studies 1 (1985): 45-57.

Hosmer, D., and S. Lemeshow. Applied Logistic Regression. New York, Chichester, Brisbane, Toronto, and Singapore: John Wiley \& Sons, 1989.

Hsieh, C. T., and B. C. Liu. "Pursuance of Better Quality Life: On the Long Run, Better Quality of Life Is the Most Important Factor in Migration." American Journal of Economics and Sociology 42 (1983): 431-440.

Knapp, T. A., and P. E. Graves. "On the Role of Amenities in Models of Migration and Regional Development." Journal of Regional Science 29 (1989): 71-87.

Krumm, R. J. "Regional Labor Markets and the Household Migration Decision." Journal of Regional Science 23 (1983): 361-376.

Linneman, P., and P. Graves. "Migration and Job Change: A Multinomial Logit Approach." Journal of Urban Economics 14 (1983): 263-279.

Liu, B. "Differential Net Migration Rates and the Quality of Life." Review of Economics and Statistics (August 1975): 329-337. 
Marsh, B. "Continuity and Decline in the Anthracite Towns of Pennsylvania." Annals, Association of American Geographers 77 (1987): 337-352.

Morgan, D. J. "Patterns of Population Distribution: A Residential Preference Model and Its Dynamic." Research Paper no. 176. Chicago: University of Chicago, Department of Geography, 1978.

Ploch, L. A. "The Reversal in Migration Patterns-Some Rural Development Consequences." Rural Sociology 43 (1978): 293-303.

Porell, F. W. "Intermetropolitan Migration and the Quality of Life." Journal of Regional Science 22 (1982): 137-158.

Rudzitis, G. "Migration, Sense of Place, and Nonmetropolitan Vitality." Urban Geography 12 (1991): 80-88.

"Migration, Places, and Nonmetropolitan Development." Urban Geography 10 (1989): 396-411.

"Determinants of Central City Migration Patterns of Older

Persons." In Location and Environment of the Elderly Population, edited by

S. Golant. Washington, D.C.: Halsted Press, 1979.

Rudzitis, G., and H. E. Johansen. "How Important Is Wilderness? Results From a United States Survey." Environmental Management 15 (1991a): 227-233.

"Motivations of Metropolitan and Nonmetropolitan Migrants to

High-Amenity Counties." Urban Geography (1991b): forthcoming .

"Amenities, Migration and Nonmetropolitan Regional

Development." Report to the National Science Foundation. 1989.

Sjaastad, L. "The Costs and Returns of Human Migration." Journal of Political Economy 70. Supplement (1962): 80-93.

Sofranko, A. J., and J. O. Williams. Rebirth of Rural America: Rural Migration in the Midwest. Ames, Iowa: Iowa State University, 1980.

Stevens, J. B. "The Demand for Public Goods As a Factor in the Nonmetropolitan Migration Turnaround." In New Directions in Urban-Rural Migration, edited by D. L. Brown and J. M. Wardwell. New York: Academic Press, 1980.

Swanson, L. L. What Attracts Migrants to Nonmetro Areas? Washington, D.C.: U.S. Government Printing Office, 1986.

Ullman, E. L. "Amenities As a Factor in Regional Growth." Geographical Review 44 (1954): 119-132.

U.S. Bureau of the Census. County and City Data Book 1988. Washington D.C.: U.S. Government Printing Office, 1988.

Zuiches, J. J., and G. V. Fuguitt. "Residential Preferences and Mobility Expectations." Paper presented to American Sociological Association, New York, New York, 1976. 